\title{
Michael W. Nicolle: Canadian Leader in Neurology
}

\author{
Ario Mirian (10)
}

Keywords: Education, Postgrad Medical Education, Communication, Neuromuscular disorders, Myasthenia Gravis doi:10.1017/cjn.2020.134

The Canadian Leaders in Neurology series is an initiative of the Canadian Neurological Society whose objective is to showcase exceptional accomplishments by Canadian neurologists who are leaders in their respective fields. In this segment of the series, Ario Mirian, a neurology resident at Western University, interviews Michael W. Nicolle (Figure 1).

Dr. Nicolle is a neuromuscular specialist with many leadership roles. $\mathrm{He}$ is the Director of the electromyography (EMG) laboratory and neuromuscular group and Chief of the Division of Neurology in the Department of Clinical Neurological Sciences at Western University. He has extensive clinical expertise and academic work in myasthenia gravis and other disorders of neuromuscular transmission. He is a member of Medical/Scientific Advisory Board of the Myasthenia Gravis Foundation of America and medical advisor for the Myasthenia Gravis Coalition of Canada. He was the founder and past president of the Canadian Neuromuscular Group, an affiliate society of the Canadian Neurological Sciences Federation (CNSF).

Ario Mirian (AM): Was there a formative experience or moment which led you to the University of Oxford to pursue your Ph.D. on cellular immunology of myasthenia gravis?

Michael Nicolle (MN): I can think of a very specific conversation with Bill Brown. He was the previous director of the EMG lab when I was a resident. He said "why don't you go away to do fellowship and while you're away why don't you do a degree?"... so it came out of a single conversation with a single person. It was a great example of informal mentorship.

\section{AM: Did mentorship play a role in your career?}

MN: I think it was very important. There was no formal mentorship program back then. You had to rely on professors, senior colleagues, to help you navigate what you're going to do. If you decided to go academic it was very much word of mouth back then - who your supervisor knew that could put in a good word for you. Bill Brown knew John Newsom-Davis who was a Professor of Neurology at Oxford and he put in a good word for me and that's how things happened.

AM: I'm early in my training and have already taken a few clinical pearls from you. Were there any pearls you received that still hold true or that you regularly refer to?

MN: This is another good example of mentorship. Before I got into residency, as a medical student, I did a summer

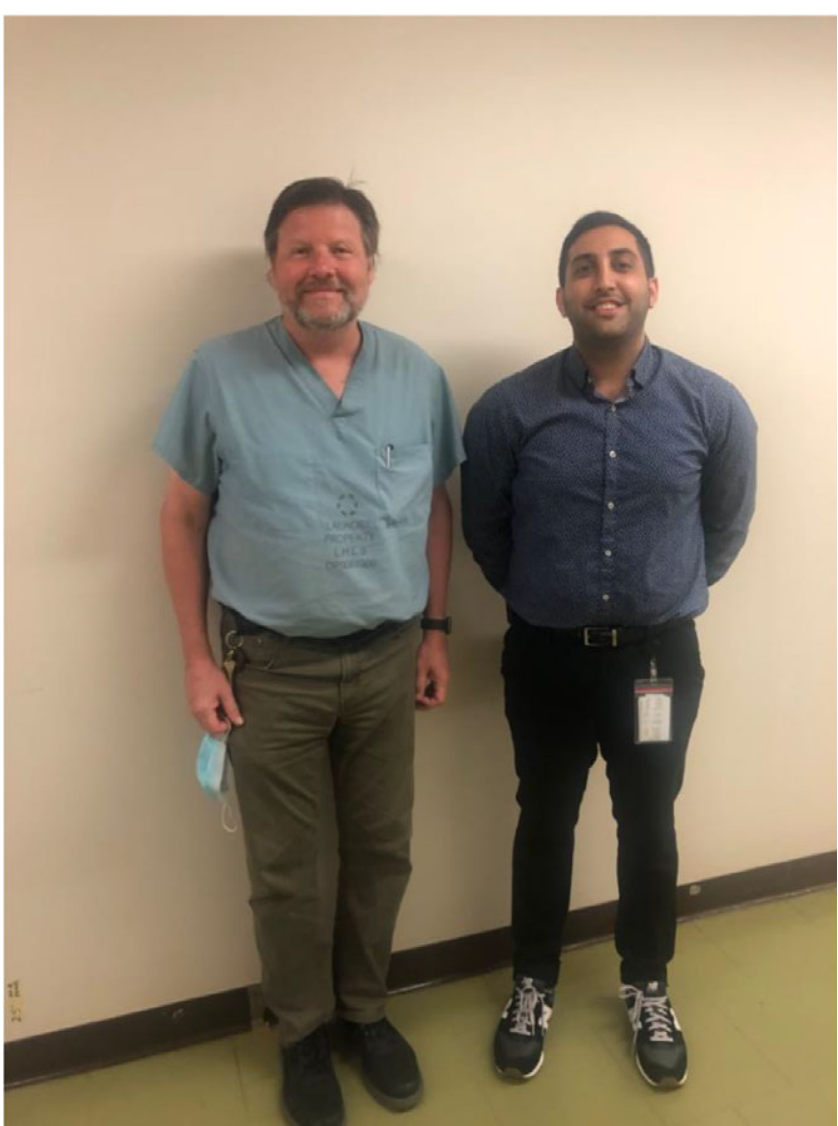

Figure 1: Michael Nicolle (left) outside of the EMG lab, with Ario Mirian (right) who conducted the interview.

research program with George Ebers who was the leader of the multiple sclerosis clinic here. I got to know him fairly well and he was the single best clinical neurologist in terms of the practical aspects of doing the neurological exam. The best teaching I got was from him in terms of clinical pearls. I remember rounding with George on one patient (he thought nothing of rounding until 8 or $9 \mathrm{pm}$ on a routine admission, but

From the Clinical Neurological Sciences, Western University, London, ON, Canada (AM) Received June 15, 2020. Final Revisions Submitted June 23, 2020. Date of AcCePtance June 24, 2020.

Correspondence to: Ario Mirian, Clinical Neurological Sciences, Western University, 339 Windermere Rd., London, ON N6A 5A5, Canada. Email: amirian2@uwo.ca 
it was worth every minute of it!) who had a bifrontal glioma with profound apathy. George went through the various primitive reflexes, culminating with him taking off his penny loafer to demonstrate a rather striking example of rooting reflex. He was full of clinical pearls in neurology and I learned a tremendous amount from him.

AM: You've had many accomplishments as a clinician, scientist, and leader within your field. Can you share one that was the most rewarding and why?

MN: I'm not so sure that's true. The Royal College work is something I'm very proud of. We managed to turn a good exam into an excellent exam over my tenure as Vice-Chair and then Chair. The Canadian Neuromuscular Group is another accomplishment. The idea of that was to have a forum of neurologists or physiatrists interested in EMG or neuromuscular disease to discuss clinical or educational matters and potential research topics. It also morphed into an annual course at the CNSF meeting.

AM: You often receive referrals within Ontario and nationwide for patients with Myasthenia Gravis and other disorders of neuromuscular transmission. How did you approach these clinical challenges throughout your career?

MN: I think there's more pressure, particularly from the patient because they often come from long distances. I see patients from all over Ontario, other provinces, and once or twice a year internationally. When they come, they come with a lot of expectations that you're going to be their saviour. You're usually the fourth, fifth, or tenth neurologist that they've seen. In that situation, there is a greater chance, in myasthenia gravis, that they don't have it even though that's a diagnosis that they've been given. That adds to the expectations because patients don't like being told that they don't have a disease that they may have lived with for the last several years. It's also very rewarding that people respect you enough that they take the time to refer you patients and that the patient has enough trust in you that they're willing to travel that distance at their time and expense to see you. I find that very rewarding.

AM: You've taken many leadership roles over your career and continue to do so. Can you tell me more about those experiences and what you think has helped you as a strong leader?

MN: I've learned a lot in my position as Chief of the Division of Neurology in the last ten years. I think listening skills are particularly important. I must say, for the first several years that I was in the role I didn't listen as much as I should have. That's something I've learned over the years; there's multiple sides to the same issue and before you take action you need to make sure you hear everyone out.

\section{AM: How have you seen the neuromuscular subspecialty} evolve over your years?

MN: Our ability to diagnose things within the neuromuscular world has grown. Back then we had to rely very much on histopathology so we were taking biopsies of nerve and muscle for things we wouldn't dream of doing now. In my world, antibody testing in myasthenia, genetic testing for a lot of the myopathies and neuropathies, weren't available back then. That's been a huge change in practice.
AM: What is the most exciting thing about the future of the neuromuscular field?

MN: The new therapeutic advances. The exciting things are the new biologicals coming out - the monoclonal antibodies. The difficulty is the expense and access. But it provides an opportunity to treat patients that we previously had nothing to offer. These are the worst of the worst patients in terms of severity and duration of disease. That to me is very exciting.

AM: What advice would you give to neurology trainees or fellows that aspire to have an academic career in neurology?

MN: Surround yourself with good people. Establish an informal or formal mentorship program. Seek out people whose opinion you value. For two reasons, one is that they can give you good advice but the second is it's a good way to network. They can put you in touch with people that can help you in your career. I think anybody that is as senior as I am, it embarrasses me to say that, but that's kind of the major contribution we can have to the next generation of neurologists is by helping the residents and fellows establish their careers. It's been very gratifying for me see numerous residents and fellows rotating through the EMG or neuromuscular clinics go on to establish successful community or academic practices. It's very rewarding to think that I contributed in a small way to that.

\section{AM: What do you do outside of neurology that keeps you} motivated?

MN: I think it's very important for physicians to have an activity, interest, or hobby outside of medicine. For me, it's photography. I'm an avid, amateur photographer. You'll often see me with my camera out on walks or on weekends. When I was a resident, the neurologists were known for wearing bowties and birdwatching. I had zero interest in birdwatching but now a number of neurologists I know of are interested in photography. So, we've gone from birdwatching to photography which is a positive change!

\section{AM: Is there anything you'd like to add?}

MN: If I had to give advice to anybody, it's to leave your options open as long as possible. If you're not absolutely sure you're interested in something, then keep going and trying different things until you settle on something that you have a passion for. You're not going to be happy in your professional life if you're not really interested in what you're doing. To me, the most exciting thing about being a neurologist is the clinical encounter. It's like being a detective. Increasingly, we get instant gratification because of the diagnostic tests that are available to us we'll know within a matter of days or weeks whether we're correct.

\section{ACKNOWLEDGMENTS}

The author would like to thank Dr. Michael Nicolle for his participation in the interview and his efforts in continuing to promote mentorship within neurology training.

\section{Disclosures}

Ario Mirian reports no disclosures pertaining to financial interest, research grant, material support, or consulting fee. 